\title{
EMERGING TRENDS IN THYROID DISEASES IN TSUNAMI HIT COASTAL AREAS OF PUDUCHERRY AND CUDDALORE, INDIA.
}

\author{
Narayanappa Shiroorkar Pradeepkumar, Reecha Singh, Noyal Mariya Joseph
}
1. Professor \& Head, Department of Pathology, Lakshmi Narayana Institute of Medical Sciences, Pondicherry, India.
2. Assistant Professor, Department of Pathology, Indira Gandhi Medical College and Research Institute, Pondicherry, India.
3. Assistant Professor, Department of Microbiology, Pondicherry Institute of Medical Sciences, Pondicherry, India.

\section{CORRESPONDING AUTHOR}

Dr. Narayanappa Shiroorkar Pradeepkumar

Professor and Head, Department of Pathology,

Sri Lakshmi Narayana Institute of Medical Sciences,

Osudu, Agaram Village, Villianur Commune,

Kudupakkam Post, Pondicherry - 605502

E-mail: drnspradeepkumar@yahoo.com

Ph: 00919345476620

ABSTRACT: BACKGROUND: Thyroid diseases are major global health problem but the incidence and prevalence of this varies from place to place. The government of India has started universal iodization of salt owing to the huge burden of thyroid diseases in the country. In 2004, the coastal regions of Puducherry and Cuddalore were flooded by tsunami. AIMS: The aim of this study is to determine the prevalence of thyroid diseases in coastal regions of Puducherry and Cuddalore. We also studied the trends in prevalence of thyroid diseases after tsunami. MATERIALS AND METHODS: All the patients undergoing thyroidectomy in a tertiary care teaching hospital in South India were included in our study. Histopathological examination of thyroidectomy specimens was performed. RESULTS: A total of 342 thyroidectomy specimens were studied. Of the 342 cases, 30 were males and 312 were females with a ratio of $1: 10.4$. Out of 342 cases, 169 (49.42\%) were non neoplastic lesions, 173 (50.58\%) were neoplastic. Of the 342 cases, $118(34.5 \%)$ cases were simple goiter, 98 (28.66\%) were adenoma, 70 (20.47\%) were papillary carcinoma, $42(12.28 \%)$ were thyroiditis, $9(2.63 \%)$ were toxic goiter and 5 $(1.46 \%)$ were follicular carcinoma. We observed an increasing trend in the prevalence of papillary carcinoma and thyroiditis after tsunami in 2004. CONCLUSIONS: There is an urgent need to establish quality assurance system to monitor iodine content in the soil, food, water and salt in the tsunami affected coastal areas. It is also necessary to study the other possible causes for papillary carcinoma and take measures to prevent it.

KEY WORDS: Thyroid, Emerging trends, Histopathology, Tsunami

INTRODUCTION:_Thyroid diseases are a major health problem both in developed and developing countries. Their incidence varies from $4-7 \%$ of the population. ${ }^{[1-4]}$ They are more in hilly terrain and away from the sea coast.[2,5-7] The prevalence of thyroid disease is $1-7 \%$ of females in UK and $4 \%$ of the population in US.[8,9] In India, thyroid diseases are endemic in many parts of Goa, Gujarat, Kerala, and the Himalayan region. The principal diseases of thyroid are simple goiter (diffuse and nodular), hyperthyroidism, hypothyroidism, thyroiditis (Hashimoto thyroiditis, granulomatous, sub-acute lymphocytic thyroiditis) and neoplasms.[2] Colloid goiter affects more than 200 million individuals throughout the world. [1, 2] FNAC is the 
most cost effective method for diagnosis of thyroid disease. ${ }^{[4,9-11]}$ Histopathology is used for the final diagnosis when FNAC is inconclusive.[4,9]

Thyroid diseases cause concern because $5-10 \%$ of them are malignant. $[1,3,9]$ Exact causes of thyroid neoplasms are not well known. Exposure to radiation and high dietary intake of iodine are the risk factors for papillary carcinoma while iodine deficiency is a risk factor for follicular carcinoma and colloid goiter.[12,13] Viral infections are predisposing factors for autoimmune thyroiditis. The government of India has started universal iodization of salt owing to the huge burden of thyroid diseases in the country. However, in view of the recent occurrence of tsunami in 2004 in the coastal areas of South India which is likely to have increased the iodine levels in the adjacent regions, there is need to know if the practice of consuming iodized salt is still necessary in the tsunami hit coastal areas.

We therefore performed this study to determine the prevalence of thyroid disease and the ongoing trends in the occurrence of various thyroid diseases in the tsunami hit coastal areas of Puducherry and Cuddalore in South India. This is the first study conducted in the tsunami hit coastal areas to observe the changing trend in the occurrence of thyroid diseases.

MATERIALS AND METHODS: This study was conducted for a period of 9 years from January 2002 to July 2010 at a tertiary care teaching hospital in Puducherry, which caters to the health care needs of the people living in the adjacent coastal areas of Puducherry and Cuddalore. We received a total of 16,979 surgical specimens, of which 354 were thyroid specimens. Of these 354 thyroid specimens received in our lab, 12 had incomplete clinical data and were therefore excluded from the study. The remaining 342 thyroid specimens obtained by total or partial thyroidectomy from clinically diagnosed thyroid cases, irrespective of age, gender, race and demographic habitat were included in the study. This study was approved by the Institute Ethics Committee.

Clinical history, examination findings and all the investigation results were noted. Careful gross examination of thyroidectomy specimen and lymph nodes (in malignancy with secondaries) was performed. Tissue bits were processed after fixation in $10 \%$ formalin, embedded in paraffin wax, thin section of 3-5 microns were taken on albuminized slide, kept at $60^{\circ} \mathrm{C}$ for 30 minutes and immersed in Xylene. These sections were stained by $\mathrm{H} \& \mathrm{E}$ and mounted with DPX.

The sections were examined by a team of experienced Pathologists. The slides were grouped according to the different thyroid lesions, age, sex and other demographic features. The results were analyzed with available data and compared with other studies. The ongoing trends in thyroid disease are also analyzed.

Statistical significances were calculated by Chi square test and Fisher's exact test. $P$ values $<0.05$ were considered statistically significant. Statistics software GraphPad InStat version 3.06 for Windows, USA was used for calculation of $P$ values.

RESULTS: We received 2.01\% (342) thyroidectomy (total as well as subtotal) specimens out of total 16,979 surgical specimens during study period. The results were analyzed with available data and compared with other studies.

Of the total 342 cases studied 312 (91.23\%) were female and only 30 (8.77\%) cases were male. The distribution of thyroid disease in relation to sex is shown in Table 1 . Highest incidence $(19.82 \%)$ of the thyroid disease was seen in the age group 26 - 30 years. The age 
distribution of the thyroid diseases is shown in Figure 1. Overall $67.54 \%$ of thyroid diseases were in the age group of 21 to 40 years.

Of the 342 cases, 118 (34.5\%) were simple colloid goiter and 98 (28.66\%) were adenomas. Malignancy was observed in 75 (21.93\%) cases. Thyroiditis and toxic goiter accounted for $42(12.28 \%)$ and 9 (2.63\%) cases respectively. The most common thyroid disease in female patients was nodular colloid goiter (110/312), while in male patients it was adenoma (10/30). Year wise follow up shows there is mild decrease in the trend of simple goiter and adenomas (Figure 2). Similar follow up for inflammatory thyroid diseases shows there is significant increase (Figure 3). But most important is there is striking increasing in trend of papillary carcinoma since last 6 years (after 2004 tsunami) (Figure 3). Follicular carcinoma and toxic goiter show mild change in trend and as their sample size small, it is difficult to give any opinion on them (Figure 2).

The comparison of the distribution of thyroid diseases in different studies is shown in Table 2. Of the 42 cases of thyroiditis observed in our study, 25 were identified as Hashimoto thyroiditis and the remaining 17 were classified as lymphocytic thyroiditis. Among the 75 cases of malignant neoplasms, 70 were morphologically sub-classified as papillary carcinoma, while the other 5 were classified as follicular carcinoma. The relative predominance of papillary carcinoma among thyroid malignancies observed in different studies is summarized in Table 3.

DISCUSSION: Thyroidectomy specimens accounted for $2.08 \%$ of the total surgical specimens received during the study period. This shows a low frequency of thyroid diseases as compared to Tsegaye B \& Ergete W, but is similar to that of Arora R. ${ }^{[2,14]}$ This could be due to the fact that people from the coastal regions of Puducherry and Goa consume lot of sea food. In addition, the soil in coastal areas is rich in iodine and consequently the food and water also have a high content of iodine.

In our study the thyroid diseases showed a very high female preponderance with female to male ratio of 10.4: 1 . This relatively very high female preponderance observed in our study in comparison to other similar studies is found to be statistically very significant. ${ }^{[1-3,10,11]}$ However, the exact reason for this difference between our study and other studies is not known. It could probably be due to severe nutritional deficiency. There is scope for further study to know the reason

In the present study, high prevalence of thyroid diseases was seen in relatively younger age group (26 - 30 years). In a study from Ethiopia, majority of the thyroid diseases occurred in the age group $30-39$ yrs.[2] Similarly, in two different studies from Kolkata (India) and Malaysia, the age group 41 - 60 yrs was observed to be commonly affected by thyroid diseases. ${ }^{[3,10]}$ The reason for the increased occurrence of thyroid diseases in younger age group in our study is not clear.

The presence of goitrogens in foods of coastal places is often considered as a reason for the predominance of simple colloid goiter in these areas. Although simple colloid goiter was the most common thyroid disorder in our study, the proportion of patients with this condition was relatively less in our study compared to other similar studies. This can be attributed to the fact that the patients from Puducherry and Cuddalore consume iodized salt and sea food rich in iodine. There is mild decrease in the trend of this simple goiter. This could be due to people's awareness about thyroid diseases and practice of preventive measures like using sea foods and iodized salt.

Journal of Evolution of Medical and Dental Sciences/Volume1/Issue5/November-2012Page-859 
In a study from Malaysia only 203 of 820 (25\%) thyroid specimens were noted to have a neoplastic condition.[3] Similarly, in a study from Bahrain 43 of 110 (39\%) thyroid specimens had neoplasms. ${ }^{[1]}$ However, in our study 173 of 342 patients (50.59\%) had thyroid neoplasms (adenomas, papillary carcinoma and follicular carcinoma). The increased occurrence of thyroid malignancies in our study in comparison to the above two studies was statistically very significant ( $P$ value $<0.0001$ vs. Malaysia study and $P$ value 0.0275 vs. Bahrain study).

The present study shows an increasing trend in the prevalence of neoplasm especially thyroid malignancy. The increasing incidence of malignancy is everyone's concern. It is necessary to find the cause and take preventive measures for the same. Compared to other studies, statistically significant increase in the occurrence of papillary carcinoma was observed in our study. This increasing incidence of papillary carcinoma in the present study is alarming.

There was also a striking increase in the trend of papillary carcinoma in the present study. The risk factors for papillary carcinoma are radiation, high intake of iodine. The flooding of the coastal regions of Puducherry and Cuddalore during the tsunami in 2004 could have increased the iodine content of the soil. Despite the increased iodine levels in the soil due to tsunami the people still continue to consume iodized salt, which probably could be the reason for increased occurrence of papillary carcinoma in our population. There is an urgent need to establish quality assurance system to monitor iodine content in the soil, food, water and salt in the tsunami affected coastal areas. It is also necessary to study the other possible causes for papillary carcinoma and take measures to prevent it. Another common lesion encountered in our study was thyroiditis. It is comparatively higher than the incidence in different studies, but is less than the study by Richard et al.[1-4,9,15,16] In our study we observed an increase in the incidence of inflammatory thyroid diseases almost similar to papillary carcinoma. So, we suspect that the increased occurrence of these two conditions might be interrelated.

Thyrotoxicosis was rare in our study and was observed in only $1.95 \%$ of the cases. It is similar to studies done in Pakistan and Malaysia, but is lower than studies done in Bahrain.[1,4,11] The incidence of thyrotoxicosis is not showing much change in its trend. The incidence of follicular carcinoma was decreasing. But the sample sizes of these two conditions were too small to observe any significant trend.

In conclusion, our Histopathological study emphasizes the fact that there was a higher predominance of thyroid disease in female as compared with other studies. The thyroid diseases were seen in relatively younger age group. Neoplasms are the commonest thyroid lesions necessitating thyroidectomy. There was higher incidence of papillary carcinoma and thyroiditis as compared with other studies. There was also a striking increase in the trend of papillary carcinoma after tsunami. However, further studies in the other tsunami affected areas are necessary to confirm this increased incidence as there is a paucity of similar data from other tsunami hit coastal areas. There is an urgent need to establish quality assurance system to monitor iodine content in the soil, food, water and salt in the tsunami affected coastal areas. It is also necessary to study the other possible causes for papillary carcinoma and take measures to prevent it.

\section{REFERENCES:}

1. Darwish AH, Al-Sindi KA, El-Kafsi J. Pattern of thyroid disease - a histopathological study. Bahrain Med Bull 2006;28:1-6

Journal of Evolution of Medical and Dental Sciences/Volume1/Issue5/November-2012Page-860 
2. Tsegaye B, Ergete W. Histopathologic pattern of thyroid disease. East African Medical journal 2003;80:525-8

3. Htwe TT, Hamdi MM, Swethadri GK, Wong JOL, Soe MM, Abdullah MS. Incidence of thyroid malignancy among goitrous thyroid lesion from Sarawak General Hospital 2000 - 2004. Singapore Med J 2009;50:724 -8

4. Nurismah MI, Sharifah NA, Usama AE, Rohaizak M, Ibrahim N. Fine needle aspiration (FNA) cytology of the thyroid: a cyto-histopathological study of 361 cases in Hospital Universiti Kebangsaan Malaysia. Med and Health 2007;2:58-65

5. Kumar V, Abbas AK, Fausto N. Robbins and cotran Pathologic basis of disease. 7th ed. Saunders: Elsevier Inc, 2004

6. Park K. Iodine deficiency disorders. In: Park's text book of Preventive and social Medicine. 19th ed. Jabalpur: Banarsidas Bhanot, 2007. p. 510-1

7. Das S. The Thyroid and Parathyroids. In: A concise textbook of Surgery. 4th ed. New Delhi: Das S, 2006. p.644-78

8. Walker BR, Strachan MWJ. Endocrine disease. In: Boon NA, Colledge NR, Walker BR, Hunter JAA editors. Davidson's principles and practice of Medicine. 20th ed. Edinburgh: Churchill Livingstone, 2006. p.744-62

9. Prinz RA, O'Morchoe PJ, Barbato AL, Braithwaite SS, Brooks MH, Emanuele MA, et al. Fine needle aspiration biopsy of thyroid nodules. Ann Surg 1983;198:70-3

10. Guhamallick M, Sengupta S, Bhattacharya NK, Basu N, Roy S, Ghosh AK, Chowdhury M. Cytodiagnosis of thyroid lesions - usefulness and pitfalls: a study of 288 cases. J Cytol. January 2008;25:6-9

11. Kumar S, Aqil S, Dahar A. Role of fine needle aspiration cytology in thyroid diseases. Journal of Surgery Pakistan (International) 2008;13:22-5

12. Krukowski ZH. The Thyroid gland and the thyroglossal tract. In: Russell RCG, Williams NS, Bulstrode CJK editors. Bailey and love's short practice of surgery 23rd ed. London: Hodder Arnold, 2008. p. 771-806

13. Dorairajan N, Pandiarajan R, Yuvaraja S. A Descriptive study of papillary carcinoma in a teaching hospital in Chennai, India. Asian Journal of Surgery 2002;25:300-4

14. Arora R, Dias A. Iodine and thyroid cancer in Goa. Online J Health Allied Scs 2006; 5:1-3

15. Perros P. Thyrotoxicosis and Pregnancy. PLoS Med 2005;2:e370

16. Desailloud R, Hober D. Viruses and thyroiditis: an update. Virology Journal 2009;6:5

Table 1. Sex distribution of thyroid disease by different studies

\begin{tabular}{|l|c|c|c|c|}
\hline \multicolumn{1}{|c|}{$\begin{array}{c}\text { Place } \\
\text { (Reference no.) }\end{array}$} & Female (\%) & Male (\%) & $\begin{array}{c}\text { No. of patients } \\
\text { studied }\end{array}$ & Pvalue* \\
\hline $\begin{array}{l}\text { Puducherry } \\
\text { (Present study) }\end{array}$ & $312(91.23)$ & $30(08.7)$ & 342 & ---- \\
\hline Kolkata (10) & $173(69.5)$ & $76(30.5)$ & 249 & $<0.0001$ \\
\hline Malaysia (3) & $677(82.6)$ & $143(17.4)$ & 820 & 0.0002 \\
\hline Bahrain (1) & $84(76.4)$ & $26(23.6)$ & 110 & $<0.0001$ \\
\hline Ethiopia (2) & $628(80.5)$ & $152(19.5)$ & 780 & $<0.0001$ \\
\hline Pakistan (11) & $60(67.4)$ & $29(32.6)$ & 89 & $<0.0001$ \\
\hline
\end{tabular}

* - $P$ value with reference to the present study

Journal of Evolution of Medical and Dental Sciences/Volume1/Issue5/November-2012Page-861 
Table 2. Comparison of the distribution of thyroid diseases in different studies

\begin{tabular}{|c|c|c|c|c|c|}
\hline $\begin{array}{c}\text { Place } \\
\text { (Reference no.) }\end{array}$ & $\begin{array}{l}\text { Simple Colloid } \\
\text { goitre (\%) }\end{array}$ & $\begin{array}{c}\text { Toxic } \\
\text { goitre } \\
\text { (\%) }\end{array}$ & $\begin{array}{c}\text { Thyroiditis } \\
\text { (\%) }\end{array}$ & $\begin{array}{c}\text { Benign } \\
\text { (Adenoma) } \\
(\%)\end{array}$ & $\begin{array}{c}\text { Malignant } \\
\text { (\%) }\end{array}$ \\
\hline $\begin{array}{l}\text { Puducherry } \\
\text { (Present study) }\end{array}$ & 34.5 & 2.63 & 12.28 & 28.65 & 21.93 \\
\hline Malaysia (4) & 71.0 & 0.3 & 0.3 & 11.0 & 17.4 \\
\hline Malaysia (3) & 70.4 & 4.0 & 0.9 & 18.1 & 6.7 \\
\hline Bahrain (1) & 45.5 & 8.0 & 7.0 & 15.5 & 24.0 \\
\hline Ethiopia (2) & 76.9 & 0 & 2.1 & 12.8 & 8.2 \\
\hline Kolkata (10) & & 79.1 & & 10.8 & 10.0 \\
\hline Goa (14) & \multicolumn{4}{|c|}{89.4} & 10.6 \\
\hline Pakistan (11) & \multicolumn{4}{|c|}{90.0} & 10 \\
\hline
\end{tabular}

Table 3. Comparison of the predominance of papillary carcinoma among thyroid malignancies in different studies

\begin{tabular}{|r|l|c|c|c|c|}
\hline S. No. & $\begin{array}{l}\text { Place of Study } \\
\text { (Reference no.) }\end{array}$ & $\begin{array}{c}\text { No. of } \\
\text { papillary } \\
\text { carcinom } \\
\text { a }\end{array}$ & $\begin{array}{c}\text { Total no. of } \\
\text { thyroid } \\
\text { malignancies }\end{array}$ & $\begin{array}{c}\text { \% of } \\
\text { papillary } \\
\text { carcinoma }\end{array}$ & P value * \\
\hline 1. & $\begin{array}{l}\text { Puducherry (Present } \\
\text { study) }\end{array}$ & 70 & 75 & 93.3 & - --- \\
\hline 2. & Ethiopia (2) & 49 & 64 & 76.6 & 0.0103 \\
\hline 3. & Malaysia (3) & 39 & 55 & 70.9 & 0.0014 \\
\hline 4. & Goa (14) & 36 & 66 & 54.5 & $<0.0001$ \\
\hline
\end{tabular}

* - $P$ value with reference to the present study 


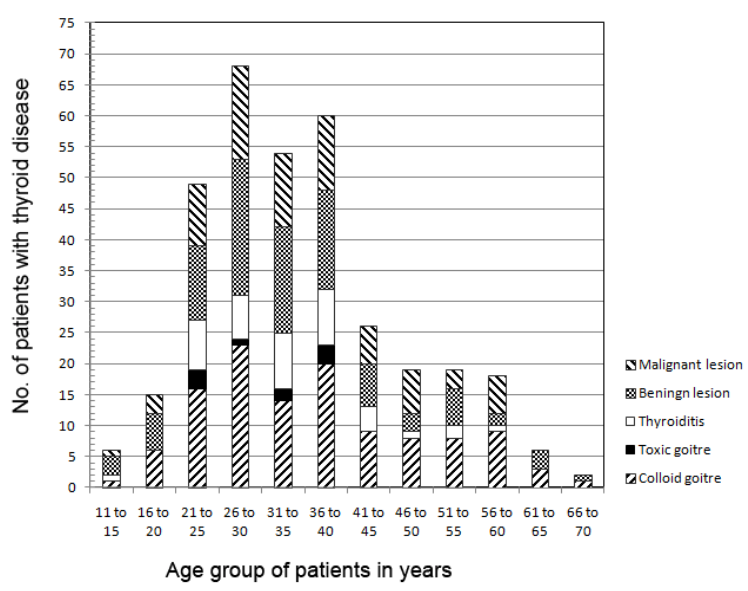

Figure 1. Age distribution of different thyroid diseases in our study

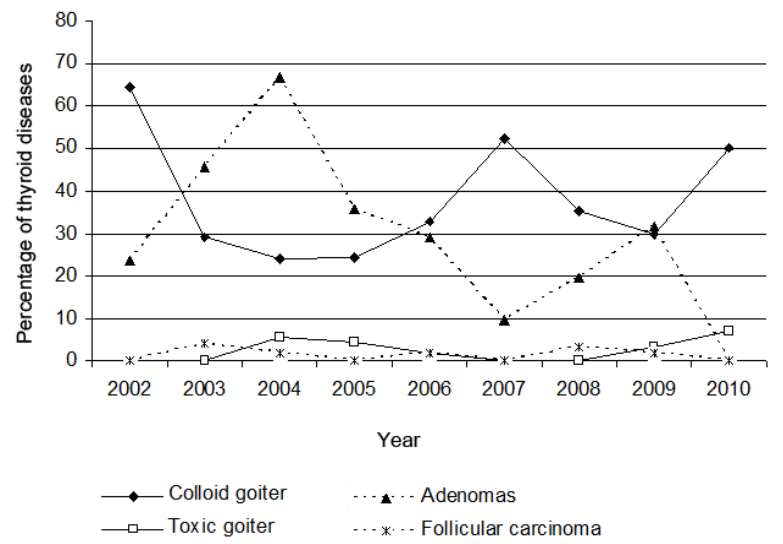

Figure 2. Trend in occurrence of colloid goiter, toxic goiter, adenomas and follicular carcinoma

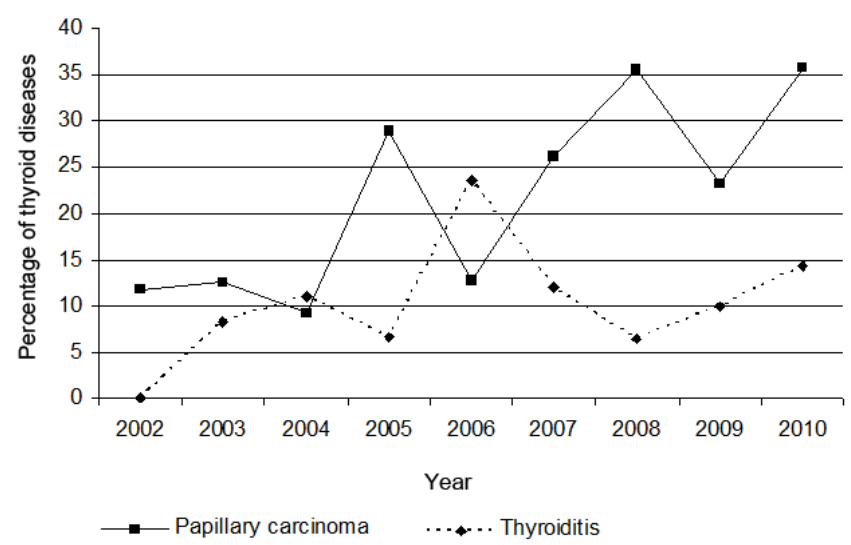

Figure 3. Trend in occurrence of thyroiditis and papillary carcinoma 